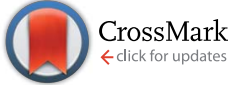

Cite this: J. Anal. At. Spectrom., 2017, 32,843

\section{Direct determination of zinc in plasma by graphite furnace atomic absorption spectrometry using palladium/magnesium and EDTA matrix modification with high temperature pyrolysis $\uparrow$}

\author{
Brian J. Stevens, ${ }^{a}$ Dominic J. Hare, ${ }^{\text {ab }}$ Irene Volitakis, ${ }^{a}$ Robert A. Cherny ${ }^{a}$ \\ and Blaine R. Roberts ${ }^{\star a c}$
}

High prevalence of zinc deficiency stemming from malnutrition, gastrointestinal diseases and low dietary intake accounts for detection of zinc in plasma being a frequently requested clinical pathology assay. Serum and plasma zinc determination by graphite furnace atomic absorption spectrometry (GFAAS) has previously been hampered by significant interfering species and intolerance to high pyrolysis temperatures. In this Technical Note, we report a GFAAS method developed to overcome these restrictions by employing two matrix modifiers and a high pyrolysis temperature. Serum and plasma samples were diluted twenty times with an Antifoam/Triton-X-100 diluent and measured against aqueous standards similarly diluted, without the use of Zeeman correction. Interference from chloride was eliminated using a combination of two matrix modifiers: a magnesium/palladium mixture combined with $1 \%(\mathrm{w} / \mathrm{v})$ aqueous ethylenediaminetetraacetic acid (EDTA). This allowed a pyrolysis temperature of $1000{ }^{\circ} \mathrm{C}$ to be used, which resulted in the complete removal of chloride interference. The accuracy of the method was verified by direct comparison with inductively coupled plasma-mass spectrometry (ICP-MS) and flame atomic absorption spectrometry (FAAS); analysis of a commercial reference material (Seronorm); and by analytical recovery studies.
Received 23rd January 2017 Accepted 20th February 2017

DOI: $10.1039 / \mathrm{c} 7 \mathrm{ja00033b}$

rsc.li/jaas
Accurate measurement of serum Zn was only made possible with the development of flame atomic absorption spectrometry (FAAS). Among the most commonly available analytical techniques for biological materials, FAAS is considered the 'gold standard' for Zn because of its speed, sensitivity, accuracy and relative freedom from interference. Initially the technique required inconveniently large sample volumes (1-2 mL), although microsampling devices have been developed to overcome this limitation.

Further advances came with the development of graphite furnace GFAAS during the 1970s, with practicable sample volumes of a few microliters, and this initially appeared to offer considerable improvement for $\mathrm{Zn}$ analysis. Unfortunately, new limitations appeared in the form of the high volatility of $\mathrm{Zn}$ (leading to premature loss of analytes at necessary temperatures), severe interference from ions such as chloride $\left(\mathrm{Cl}^{-}\right)$and sulfate $\left(\mathrm{SO}_{4}{ }^{2-}\right)$, both present at high concentrations in biological fluids, and the significant risk of environmental contamination. Efforts to solve these problems were demonstrated by the publication of six reports of GFAAS methods for $\mathrm{Zn}$ analysis in the two-year period of 1981-1982..$^{6-11}$ However, some of these methods used very high dilutions of serum samples, potentially leading to contamination issues and reducing achievable sensitivity.

\footnotetext{
${ }^{a}$ The Florey Institute of Neuroscience and Mental Health, The University of Melbourne, Parkville, Victoria, Australia. E-mail: blaine.roberts@florey.edu.au; Tel: +61 39035 6635

${ }^{b}$ Elemental Bio-imaging Facility, University of Technology Sydney, Broadway, New South Wales, Australia

${ }^{c}$ Co-operative Research Centre for Mental Health, Australia; Web: http://www. mentalhealthcrc.com

$\dagger$ Electronic supplementary information (ESI) available: Supplementary figure. See DOI: $10.1039 / \mathrm{c} 7 \mathrm{ja} 00033 \mathrm{~b}$
} 
Shaw et $a .^{10}$ attempted to overcome matrix interference by preparing calibration standards in serum pretreated with a Chelex-100 resin to decrease the endogenous $\mathrm{Zn}$ content. The results compared favorably with those of FAAS. Accominotti et al. $^{\mathbf{1 2}}$ used ammonium phosphate as a matrix modifier, a 20fold dilution and Zeeman correction with a L'vov platform in the furnace, with external calibration performed using aqueous standards. Zinc has also been successfully measured in slurries of tissue samples prepared in solutions of tetramethylammonium hydroxide. ${ }^{13}$

Slavin and colleagues studied in detail the interference caused by $\mathrm{Cl}^{-}$in GFAAS. ${ }^{14}$ The loss of analytes can occur during the pyrolysis stage due to the presence of volatile metal chlorides, or during the atomisation stage due to prevention of ground-state atom formation. They explored the use of a combination of nitric acid $\left(\mathrm{HNO}_{3}\right)$ and magnesium $\left(\mathrm{Mg}^{2+}\right)$ to control $\mathrm{Cl}^{-}$interference, and used specially designed graphite tubes and platforms, but were not able to entirely eliminate the problem. Later, Akman and Döner ${ }^{15}$ studied $\mathrm{Zn}$ and sodium chloride $(\mathrm{NaCl})$ signals with the use of a special dual cavity platform.

In our laboratory, like many employing GFAAS, we do not have access to Zeeman correction or use platform technology, and thus we were required to develop alternative methods for accurate and precise $\mathrm{Zn}$ measurement. In this Technical Note, we report a novel method employing a combination of matrix modifiers ( $\mathrm{Mg}$, palladium (Pd) and ethylenediaminetetraacetic acid [EDTA]) and high temperature to remove $\mathrm{Cl}^{-}$interference, while simultaneously permitting the direct use of aqueous standards with deuterium correction.

\section{Methods and materials}

\section{Instrumentation}

All analyses were performed on a Varian Model AA240 atomic absorption spectrometer fitted with a GTA120 graphite tube atomiser with coated partitioned tubes and a programmable sample dispenser (Model PSD120; Agilent Technologies, Mulgrave, Australia). Instrumental conditions are listed in Table 1.

\section{Decontamination of glass and plasticware}

All glassware was soaked in 5\% (v/v) Decon-90 (Decon Laboratories, United Kingdom) in water. Afterwards, the glassware was rinsed several times in deionised water, and then in $2 \%(\mathrm{w} / \mathrm{v})$ aqueous di-sodium EDTA (Sigma Aldrich, Castle Hill,

Table 1 GFAAS operational parameters

\begin{tabular}{ll}
\hline Wavelength & $213.9 \mathrm{~nm}$ \\
Spectral bandwidth & $1.0 \mathrm{~nm}$ \\
Lamp current & $5.0 \mathrm{~mA}$ \\
Furnace & Partition tube (coated) \\
Carrier gas & Ar \\
Background correction & Deuterium \\
Calibration mode & Concentration \\
Measurement mode & Peak area \\
Calibration & Quadratic
\end{tabular}

Wavelength

Spectral bandwidth

Lamp current

Furnace

Carrier ga

Background correction

Calibration
Australia). The glassware was rinsed again thoroughly before use. Plastic vials for the sample dispenser were soaked in $2 \%$ aqueous EDTA and thoroughly rinsed in deionised water and dried with compressed air. The absence of $\mathrm{Zn}$ in the washed vials was confirmed by GFAAS analysis of the blank diluent.

\section{Reagents and standard solutions}

All reagents were of analytical grade. Deionised water (18.2 M 2 ; Merck, Kilsyth, Australia) was used throughout. The diluent was an aqueous mixture of $0.05 \%$ (v/v) Triton X-100 and 0.05\% Antifoam B Emulsion (Sigma Aldrich). The first matrix modifier was prepared by adding together equal volumes of $63.3 \mathrm{mg}$ of palladium(II) acetate $\left(\left(\mathrm{CH}_{3} \mathrm{COO}\right)_{2} \mathrm{Pd}\right.$; Sigma Aldrich) in $10 \mathrm{~mL}$ of water and $34.6 \mathrm{mg}$ of magnesium nitrate hexahydrate $\left(\mathrm{Mg}\left(\mathrm{NO}_{3}\right)_{2} \cdot 6 \mathrm{H}_{2} \mathrm{O}\right.$; Sigma Aldrich) in $10 \mathrm{~mL}$ of water, prepared freshly for each analysis. The second matrix modifier was a $1 \%(\mathrm{w} / \mathrm{v})$ aqueous solution of EDTA disodium salt (Univar, Thermo Fisher, Scoresby, Australia).

An intermediate $\mathrm{Zn}$ standard was prepared by diluting $1.0 \mathrm{~mL}$ of stock $1000 \mathrm{mg} \mathrm{L}^{-1} \mathrm{Zn}$ standard (in $1 \% \mathrm{HNO}_{3}$; Agilent Technologies) to $1 \mathrm{~L}$ with deionised water. The working standard of $100 \mu \mathrm{g} \mathrm{L}^{-1} \mathrm{Zn}$ was prepared freshly for use by diluting $1.0 \mathrm{~mL}$ of intermediate standard to $10 \mathrm{~mL}$ with the Triton-X/ Antifoam diluent. The quality control material used was Seronorm Trace Elements Serum L-1 (Sero AS, Billingstad, Norway).

\section{Results and discussion}

\section{Determination of pyrolysis and atomisation temperatures}

Various studies have cited the use of metallic and non-metallic matrix modifiers to overcome chloride interference. The highest pyrolysis temperature described hitherto was $800{ }^{\circ} \mathrm{C}$, with ammonium phosphate used as the matrix modifier. ${ }^{12}$ We found that this method produced both non-linear calibrations and incomplete recovery of $\mathrm{Zn}$. Welz et al. ${ }^{\mathbf{1 6}}$ presented a very detailed examination on the use of a combined $\mathrm{Mg}$ and $\mathrm{Pd}$ matrix modifier for 21 elements including Zn. The study was performed with solutions of the metals in dilute nitric acid, with and without added $\mathrm{Cl}^{-}$and $\mathrm{SO}_{4}{ }^{2-}$. The results showed that for most metals the use of this modifier allowed for a significant increase in the pyrolysis temperature, thus eliminating chloride interference.

The use of a $\mathrm{Mg} / \mathrm{Pd}$ modifier in the measurement of plasma Zn was tested in the present study. Using appropriate instrumental conditions for $\mathrm{Zn}$ (Table 1) a furnace program was developed (Table 2). The usual GFAAS practice of halting gas flow during the atomisation stage was not used in this case due to the high sensitivity of the $\mathrm{Zn}$ signal. Alternative strategies to reduce sensitivity such as a smaller volume (i.e. $5 \mu \mathrm{L}$ ) or higher dilution factors were considered to introduce unnecessary risk of inaccuracy or contamination, respectively. After developing a suitable drying program with aqueous $\mathrm{Zn}$ standards, a series of pyrolysis and atomisation temperatures (Fig. 1) were examined. From these data, a pyrolysis temperature of $1000{ }^{\circ} \mathrm{C}$ and an atomisation temperature of $1700^{\circ} \mathrm{C}$ were selected for further experiments, as no loss of analytes and no $\mathrm{Cl}^{-}$interference were observed. 
Table 2 Furnace program for plasma Zn

\begin{tabular}{llrll}
\hline Step & $\begin{array}{l}\text { Temperature } \\
\left({ }^{\circ} \mathrm{C}\right)\end{array}$ & $\begin{array}{l}\text { Time } \\
(\mathrm{s})\end{array}$ & $\begin{array}{l}\text { Ar gas flow } \\
\left(\mathrm{L} \mathrm{min}^{-1}\right)\end{array}$ & Read \\
\hline Dry & 85 & 5.0 & 0.3 & No \\
Dry & 95 & 40.0 & 0.3 & No \\
Dry & 120 & 10.0 & 0.3 & No \\
Pyrolysis & 1000 & 5.0 & 0.3 & No \\
Pyrolysis & 1000 & 2.0 & 0.3 & No \\
Atomise & 1700 & 1.0 & 0.1 & Yes \\
Atomise & 1700 & 2.0 & 0.1 & Yes \\
Clean & 2650 & 2.0 & 0.3 & No
\end{tabular}

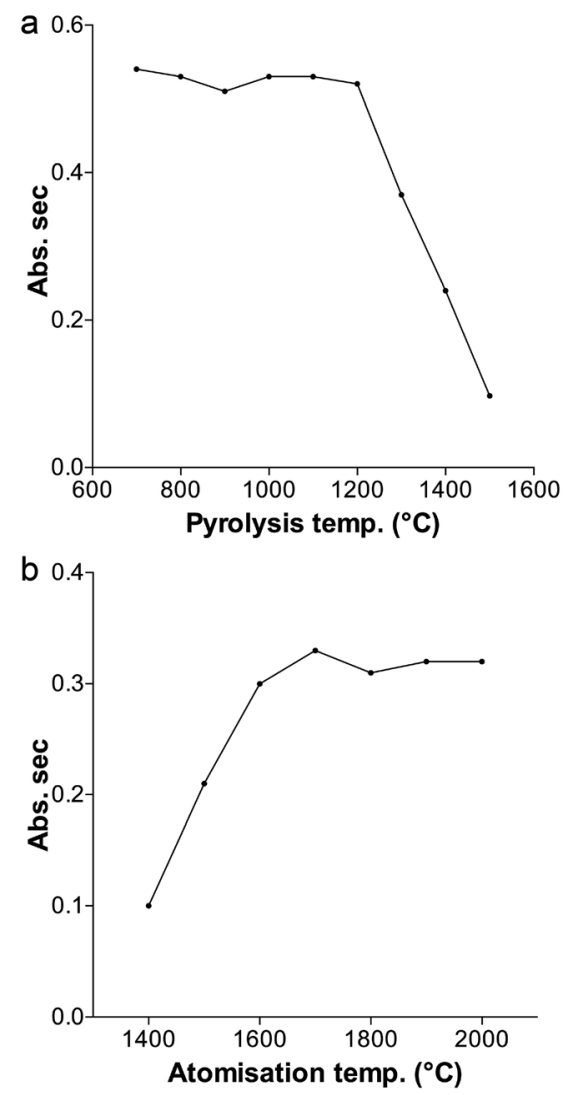

Fig. 1 Determination of pyrolysis (a) and atomisation temperatures (b) using a $2 \mu \mathrm{g} \mathrm{L}^{-1}$ aqueous $\mathrm{Zn}$ standard in a Mg/Pd modifier only.

Chloride ions are considered to be the major source of interference in the assay of $\mathrm{Zn}$ by GFAAS, the principal mechanism being the formation of highly volatile $\mathrm{ZnCl}_{2}$. In preliminary work without matrix modification it was confirmed that $\mathrm{Zn}$ is lost at pyrolysis temperatures greater than $450{ }^{\circ} \mathrm{C}$. When the present program was developed using two modifiers (see below) and a $1000{ }^{\circ} \mathrm{C}$ pyrolysis temperature, addition of chloride to the aqueous standards at physiological concentrations $(3.4-3.7 \mathrm{mg}$ $\left.\mathrm{L}^{-1}\right)^{17}$ did not affect the signal.

\section{EDTA as a secondary matrix modifier}

Disodium EDTA is a powerful chelator of $\mathrm{Zn}$, and it was hypothesised that the chelate would minimise the differences between the physical and chemical forms of $\mathrm{Zn}$ (i.e. aqueous and protein-bound). The use of EDTA and other organic matrix modifiers for GFAAS was first described by Guevremont and colleagues in the early 1980 s for the measurement of cadmium $(\mathrm{Cd})^{18}$ and $\mathrm{Zn}$ in seawater. ${ }^{19}$ The addition of EDTA was used to reduce the atomisation temperature to below that of other interfering compounds in the complex seawater matrix, which is comparable to serum with respect to levels of potential confounding interferents. It is noteworthy that these examples predated the introduction of Zeeman correction for AAS. The Zn-EDTA complex has a high stability constant $(\log K=16.5),{ }^{20}$ which is markedly higher than that of major Zn-binding proteins in plasma (e.g. $\log K=6.85$ (ref. 21) for $\mathrm{Zn}$-albumin); thus we postulated that addition of EDTA as a secondary matrix modifier would have a similar effect in plasma.
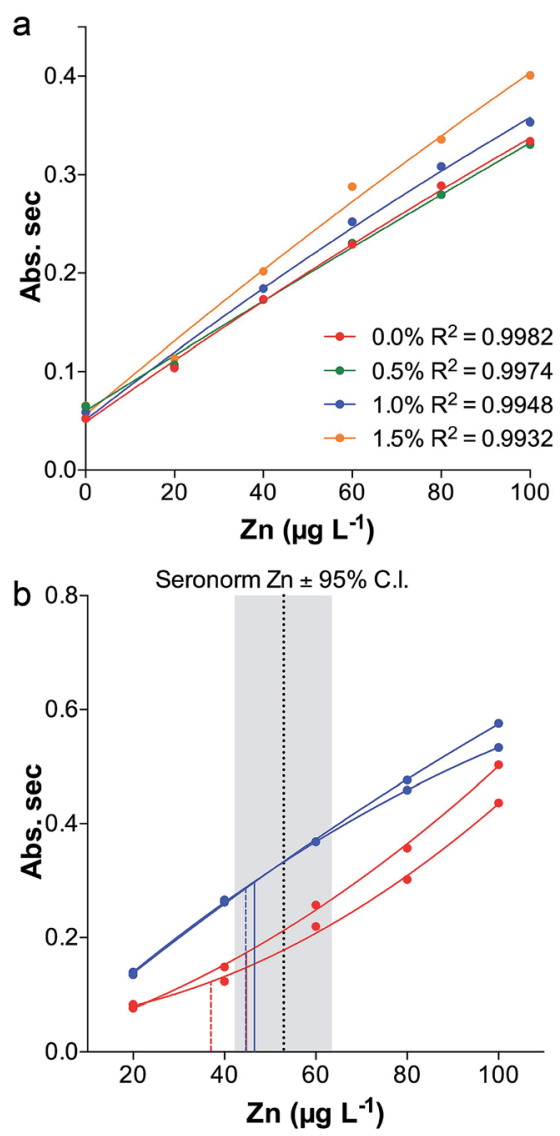

- $\mathrm{Pd} / \mathrm{Mg}$ (aqueous) $\mathrm{R}^{2}=0.9967$

-- $\mathrm{Pd} / \mathrm{Mg}$ (plasma) $\mathrm{R}^{2}=0.9987$

$\rightarrow \mathrm{Pd} / \mathrm{Mg}+1 \%$ EDTA (aqueous) $\mathrm{R}^{2}=1.000$

$\rightarrow \mathrm{Pd} / \mathrm{Mg}+1 \%$ EDTA (plasma) $\mathrm{R}^{2}=0.9994$

Fig. 2 (a) Calibration curves of $\mathrm{Zn}$ with $\mathrm{Pd} / \mathrm{Mg}$ modification and increasing concentrations of EDTA. All curves are fit using a quadratic equation. (b) Calibration curves and determination of the standard reference material (Seronorm) concentration using the Pd/Mg modifier only in aqueous and plasma matrices, and addition of $1 \%$ EDTA. Using the second modifier demonstrates that $\mathrm{Zn}$ determination falls within the acceptable certified range of values $\left(844-1269 \mu \mathrm{g} \mathrm{L}^{-1}\right.$, undiluted). 
Table 3 Spiked recovery results using Pd/Mg and 1.0\% EDTA matrix modifiers

\begin{tabular}{lllll}
\hline Sample & $\begin{array}{l}\text { Plasma Zn concentration } \\
\left(\mu \mathrm{g} \mathrm{L}^{-1}\right)\end{array}$ & $\begin{array}{l}\text { Spike concentration } \\
\left(\mu \mathrm{g} \mathrm{L} \mathrm{L}^{-1}\right)\end{array}$ & $\begin{array}{l}\text { Determined concentration } \\
\left(\mu \mathrm{g} \mathrm{L}^{-1}\right)\end{array}$ \\
\hline 1 & 1176 & 909 & $2026 \pm 101$ & $\begin{array}{l}\text { Recovery } \\
(\%)\end{array}$ \\
2 & 1267 & 1670 & $2882 \pm 144$ & 97.1 \\
3 & 496 & 2300 & $2656 \pm 133$ & 98.1 \\
4 & 574 & 1670 & $2225 \pm 111$ & 95.0 \\
\end{tabular}

To test this hypothesis, aqueous solutions of $0.5,1.0$, and $1.5 \%(\mathrm{w} / \mathrm{v})$ EDTA were prepared for trial as a second modifier. Calibration curves were then obtained using these conditions (Fig. 2a). Both 1.0 and $1.5 \%$ EDTA enhanced the $\mathrm{Zn}$ signal intensity. The $1.0 \%$ concentration was selected for further study as addition of $1.5 \%$ EDTA formed deposits in the furnace tube.

Comparison was then made between $\mathrm{Zn}$ standards prepared in the diluent and standards prepared in diluted plasma of 100 $\mu \mathrm{g} \mathrm{L^{-1 }} \mathrm{Zn}$ concentration, with and without addition of EDTA. Addition of $1.0 \%$ EDTA significantly increased the absorbance values of the aqueous standards to a point where they became almost identical to those of plasma based standards (Fig. 2b).

\section{Analysis of plasma samples and method validation}

Plasma and reconstituted Seronorm L1 controls were diluted 1 in 20 with the Triton X-100/Antifoam diluent before measurements. For the calibration curve, the automatic sampler was programmed to introduce $20,40,60,80$ and $100 \mu \mathrm{g} \mathrm{L}^{-1}$ of $\mathrm{Zn}$ standards, as described above. The volumes of the sample and the two matrix modifiers were each $10 \mu \mathrm{L}$ and co-injected into the furnace. The diluent was used as the calibration zero. Measurements were performed in triplicate and acceptable RSD was set at $<5 \%$.

Integrated absorbance (peak area) was used. The sample signal obtained with the present method produced Gaussian curves with no apparent shoulders. The calibration curve was non-linear and was appropriately fitted with a quadratic origin equation. This curvature is a result of the characteristics of the emission line width of the $\mathrm{Zn}$ hollow cathode lamp over the concentration range of the method employed. The usual GFAAS practice of halting gas flow during the atomization stage was not used here due to the high sensitivity of the $\mathrm{Zn}$ signal.

A $1: 20$ dilution of a commercially available reference material (Seronorm L1) was analysed as part of each batch to examine analytical recovery under different matrix and modifier conditions. The $\mathrm{Pd} / \mathrm{Mg}$ modification added to a plasma matrix underreported certified $\mathrm{Zn}$ concentration in Seronorm by $23.0 \%$ (measured concentration $=816 \pm 40.8 \mu \mathrm{g} \mathrm{L}^{-1}$ ), whereas measured concentrations under $\mathrm{Pd} / \mathrm{Mg}$ modified aqueous conditions $\left(1048 \pm 52.4 \mu \mathrm{g} \mathrm{L}^{-1}\right)$ and of both $\mathrm{Pd} / \mathrm{Mg}+1.0 \%$ EDTA modified aqueous $\left(1100 \pm 55 \mu \mathrm{g} \mathrm{L}^{-1}\right)$ and plasma $(1045 \pm 52 \mu \mathrm{g}$ $\mathrm{L}^{-1}$ ) matrices were within the certified range for undiluted Seronorm $\left(1059 \pm 209 \mu \mathrm{g} \mathrm{L}{ }^{-1}\right.$; the dotted black line/shaded grey area in Fig. 2b). It should be noted that the GFAAS measurements were markedly more precise than the certified value for Seronorm, which has an acceptable range for clinical use.
Spike recovery experiments were performed according to the method of Westgard and Barry; ${ }^{22}$ the results are shown in Table 3. To confirm the analytical validity of our GFAAS method, 15 clinical samples were analysed for $\mathrm{Zn}$ using inductively coupled plasma-mass spectrometry (ICP-MS), flame atomic absorption spectrometry (FAAS) with a microsampler and our own GFAAS system. Linear regression analysis showed a correlation of $R^{2}=$ 0.8596 for ICP-MS and $R^{2}=0.8309$ for FAAS (Fig. S1; ESI $\dagger$ ).

Finally, we examined the interbatch variation of the optimised $\mathrm{Pd} / \mathrm{Mg}$ and $1.0 \%$ EDTA modifier in the aqueous sample method by measuring 20 individual replicate measurements of Seronorm over a five-day period. The calculated undiluted concentration of Seronorm was $1061 \pm 14 \mu \mathrm{g} \mathrm{L}^{-1}$, which was markedly more precise than the reported 95\% confidence intervals of $1059 \pm 209 \mu \mathrm{g} \mathrm{L}^{-1}$ (98.64\% vs. 80.25\%). The calculated limit of detection (using the 3-sigma method) was $22.0 \mu \mathrm{g}$ $\mathrm{L}^{-1}$ and the limit of quantification was $24.5 \mu \mathrm{g} \mathrm{L}{ }^{-1}$. The most likely source of $\mathrm{Zn}$ contamination was impurities in the $\mathrm{Pd}$ modifier. Several Pd salts were examined, and the acetate salt had the lowest level of $\mathrm{Zn}$ contamination. The intrasample reproducibility was $2.3 \%$ and the intersample reproducibility was $5.4 \%$.

\section{Conclusion}

The accurate measurement of serum and plasma $\mathrm{Zn}$ by GFAAS has previously been hampered by matrix interference and significant volatility. The use of a combined $\mathrm{Pd} / \mathrm{Mg}$ modifier allowed a pyrolysis temperature of $1000{ }^{\circ} \mathrm{C}$ but not the use of aqueous standards.

Addition of a second modifier in the form of $1.0 \%$ aqueous EDTA in the method presented here has allowed complete compatibility between diluted plasma and aqueous zinc standards in the absence of Zeeman correction, thus providing a simple direct micro-method for use in paediatric biochemistry and other small volume situations.

\section{Acknowledgements}

We wish to thank Mr Graeme Carter and the staff of Australian Clinical Labs (Melbourne) for the measurement of plasma zinc by FAAS. Helpful advice was provided by Mr John Sanders of Varian Pty. Ltd (now Agilent Technologies), Springvale, Victoria, Australia. The Florey Institute of Neuroscience and Mental Health acknowledges the strong support from the Victorian Government and the funding from the Operational Infrastructure Support 
Grant. Financial support from the Cooperative Research Centre (CRC) for Mental Health (Grant ID: 20100104), an Australian Government Initiative and the Australian Research Council Linkage Projects Scheme (LP140100095, with Agilent Technologies) is acknowledged. DJH is a National Health and Medical Research Council Career Development Fellow (Grant ID: APP1122981) partly supported by Agilent Technologies.

\section{References}

1 A. S. Prasad, Adv. Nutr., 2013, 4, 176-190.

2 C. P. Wong, K. R. Magnusson and E. Ho, J. Nutr. Biochem., 2013, 24, 353-359.

3 E. Mocchegiani, R. Giacconi, L. Costarelli, E. Muti, C. Cipriano, S. Tesei, S. Pierpaoli, C. Giuli, R. Papa, F. Marcellini, N. Gasparini, R. Pierandrei, F. Piacenza, E. Mariani, D. Monti, G. Dedoussis, S. Kanoni, G. Herbein, T. Fulop, L. Rink, J. Jajte and M. Malavolta, Exp. Gerontol., 2008, 43, 433-444.

4 E. Ho, J. Nutr. Biochem., 2004, 15, 572-578.

5 E. Mocchegiani, C. Bertoni-Freddari, F. Marcellini and M. Malavolta, Prog. Neurobiol., 2005, 75, 367.

6 S. Levi, R. C. Fortin and W. C. Purdy, Anal. Chim. Acta, 1981, 127, 103-108.

7 N. E. Vieira and J. W. Hansen, Clin. Chem., 1981, 27, 73-77. 8 S. Matsuura, Kurume Med. J., 1982, 29, 35-47.

9 J. W. Foote and H. T. Delves, Analyst, 1982, 107, 1229-1234.
10 J. C. Shaw, A. J. Bury, A. Barber, L. Mann and A. Taylor, Clin. Chim. Acta, 1982, 118, 229-239.

11 R. C. Whitehouse, A. S. Prasad, P. I. Rabbani and Z. T. Cossack, Clin. Chem., 1982, 28, 475-480.

12 M. Accominotti, Y. Pegon and J. J. Vallon, Clin. Chim. Acta, 1988, 173, 99-106.

13 E. Muñoz-Delgado, J. C. Morote-García, R. Romero-Romero, I. López-García and M. Hernández-Córdoba, Anal. Biochem., 2006, 348, 64-68.

14 W. Slavin, G. R. Carnrick and D. C. Manning, Anal. Chem., 1984, 56, 163-168.

15 S. Akman and G. Döner, Spectrochim. Acta, Part B, 1994, 49, 665-675.

16 B. Welz, G. Schlemmer and J. R. Mudakavi, Anal. Methods, 1992, 7, 1257-1271.

17 J. R. Seifter, in Coldman-Cecil Medicine, ed. L. Goldman and A. I. Schafer, Elsevier Saunders, 25th edn, 2016.

18 R. Guevremont, R. E. Sturgeon and S. S. Berman, Anal. Chim. Acta, 1980, 115, 163-170.

19 R. Guevremont, Anal. Chem., 1981, 53, 911-914.

20 T. E. Furia, CRC Handbook of Food Additives, CRC Press, 2nd edn, 1973, vol. 1.

21 J. Masuoka and P. Saltman, J. Biol. Chem., 1994, 269, 2555725561.

22 J. O. Westgard and P. L. Barry, Lab. Med., 1989, 20, 377-384. 